SANDIA REPORT

SAND97-0544 - UC-700

Unlimited Release

Printed March 1997

\title{
Initial Development of Efficient, Low-Debris Laser Targets for the Sandia Soft X-Ray Projection Lithography Effort
}

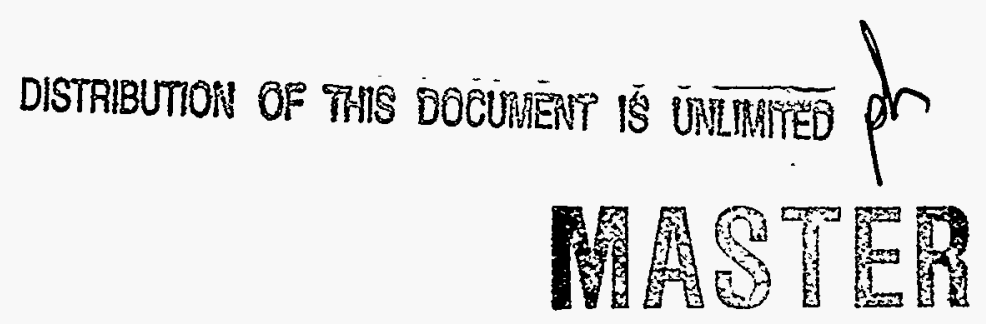

Paul D. Rockett, John A. Hunter, Glenn D. Kubiak, Kevin D. Krenz; Kurt:W.Berger, Steve J. Haney, Rick Ștulen

Prepared by

Sandia National Laboratories

Albuquerque, New Mexico 87185 and Livermore, California 94550 for the United States Department of Energy under Contract DE-AC04-94AL'85000

RECEIVED $\therefore$ W

Approved for public release; distribution is unilimited AP? 011997

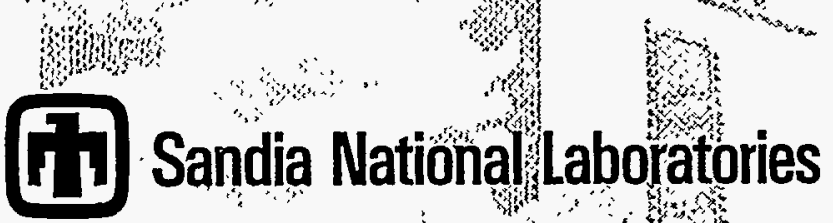

\section{O STI}

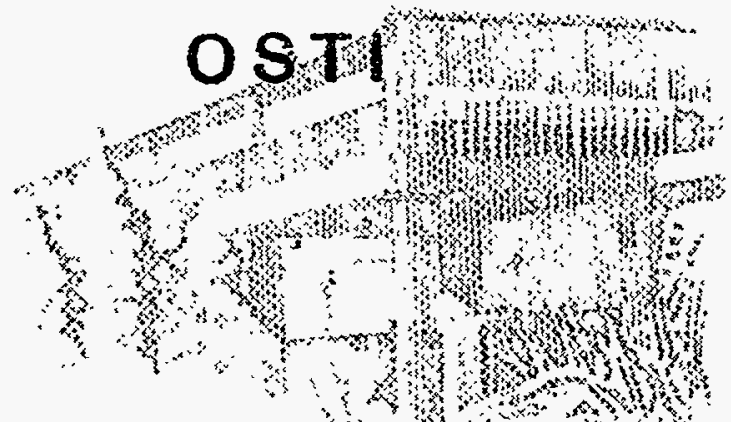

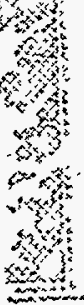

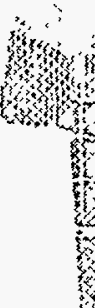

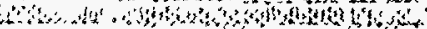

and

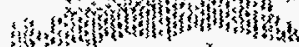

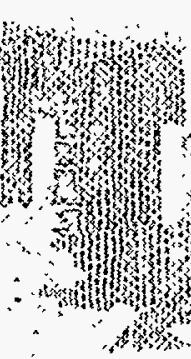


Issued by Sandia National Laboratories, operated for the United States Department of Energy by Sandia Corporation.

NOTICE: This report was prepared as an account of work sponsored by an agency of the United States Government. Neither the United States Government nor any agency thereof, nor any of their employees, nor any of their contractors, subcontractors, or their employees, makes any warranty, express or implied, or assumes any legal liability or responsibility for the accuracy, completeness, or usefulness of any information, apparatus, product, or process disclosed, or represents that its use would not infringe privately owned rights. Reference herein to any specific commercial product, process, or service by trade name, trademark, manufacturer, or otherwise, does not necessarily constitute or imply its endorsement, recommendation, or favoring by the United States Government, any agency thereof, or any of their contractors or subcontractors. The views and opinions expressed herein do not necessarily state or reflect those of the United States Government, any agency thereof, or any of their contractors.

Printed in the United States of America. This report has been reproduced directly from the best available copy.

Available to DOE and DOE contractors from

Office of Scientific and Technical Information

P.O. Box 62

Oak Ridge, TN 37831

Prices available from (615) 576-8401, FTS 626-8401

Available to the public from

National Technical Information Service

U.S. Department of Commerce

5285 Port Royal Rd

Springfield, VA 22161

NTIS price codes

Printed copy: A03

Microfiche copy: A01 


\section{DISCLAIMER}

Portions of this doeument may be illegible in electronic image products:- Images:are:produced from the best available original document: 
SAND97-0544

Unlimited Release

Printed March 1997
Distribution

Category UC-700

\title{
Initial Development of Efficient, Low-Debris Laser Targets for the Sandia Soft X-ray Projection Lithography Effort
}

\author{
Paul D. Rockett \\ Airborne Sensors and Integration Department \\ John A. Hunter \\ Nanostructure and Semiconductor Physics Department \\ Sandia National Laboratories \\ P. O. Box 5800 \\ Albuquerque, New Mexico 87185-0859
}
Glenn D. Kubiak, Kevin D. Krenz, Kurt W. Berger, Steve J. Haney, and Rick Stulen Advanced Electronics Mfg. Technologies Department

Sandia National Laboratories

Livermore, California 94551-9409

\begin{abstract}
During the fiscal years 92-94 a joint group from Sandia/New Mexico and Sandia/California studied the development of new laser-plasma targets for projection x-ray or EUV (extreme ultraviolet) lithography. Our experimental and theoretical analyses incorporated target design as an integral part of the lithographic optical system. Targets studied included thick solid targets, thin-foil metal-coated targets, and cryogenic targets. Our complete measurement suite consisted of $x$-ray conversion efficiency measurements, source size imaging, source $x$-ray angular distribution measurements, debris collection, and source EUV spectrum. Target evaluation also included the variation of laser characteristics, such as, laser intensity, spot size, wavelength, pulselength, and pulseshape.

Over the course of these experiments we examined targets using $\mathrm{KrF}(248 \mathrm{~nm}), \mathrm{XeCl}(308 \mathrm{~nm})$, and $\mathrm{CO}_{2}(10.6 \mu \mathrm{m})$ lasers. While debris issues now dominate research in this area, final details were concluded on our understanding of material spectra and radiation transport of $13 \mathrm{~nm}$ light in laser-plasmas. Additionally, conclusive results were obtained with $308 \mathrm{~nm}$ light, showing the pulselength threshold below which plumes no longer limited the transmission of (and thus the conversion efficiency to) $13 \mathrm{~nm}$ radiation.
\end{abstract}




\section{Acknowledgment}

The authors gratefully acknowledge the aid provided by Dr. Harry Shields and Michael Powers from Jamar Technology Co. Inc. for their work on acquiring laserplasma data with their $\mathrm{XeCl}$ laser. They also thank Prof. See Leang Chin of the University of Laval for his support in the use of his short pulsed $\mathrm{CO}_{2}$ laser to evaluate the effects of long wavelengths on $x$-ray conversion efficiency. 


\section{Contents}

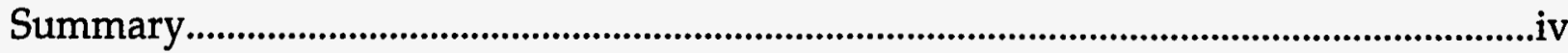

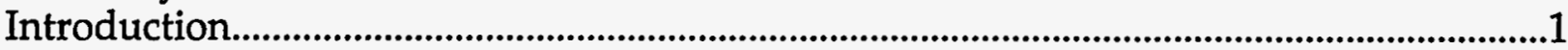

Laser-Plasma Source Characterization...............................................................................2

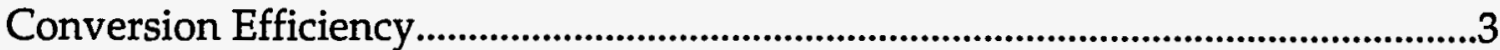

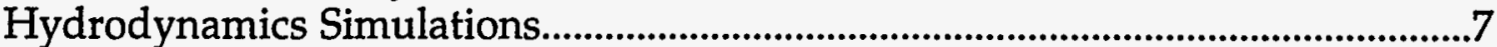

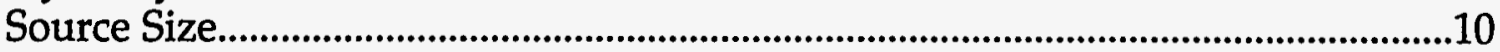

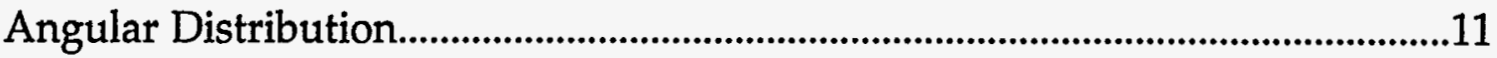

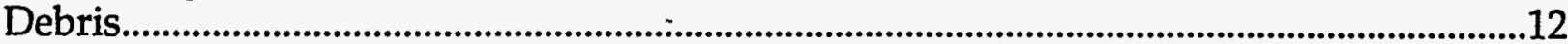

Production of Plasma Source Ejecta.............................................................................13

Suppression of Target Ejecta..............................................................................................14

Effects of Target Ejecta........................................................................................................15

Debris Mitigation................................................................................................................15

VUV Spectroscopy of Laser-plasma Sources..........................................................................17

VUV Shuttering Explained....................................................................................................20

Conclusion..............................................................................................................................21

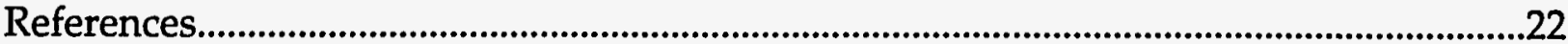

\section{Figures}

1 Conversion Efficiency for $248 \mathrm{~nm}$ and $308 \mathrm{~nm}$ light into the VUV with 32 ns and 4.5 ns pulses, respectively

2 Spectral response curves for three of the four $x$-ray diode units.......................................5

3 X-ray Diode Signals from short and long pulse excimer laser-plasmas, showing the higher temperature obtained at shorter pulselengths.............................6

4 Comparison of X-ray Diode data between a $\mathrm{CO}_{2}$ laser -plasma and a $\mathrm{XeCl}$ laserplasma, showing high temperatures and equivalent conversion efficiencies at dramatically different intensities......................................................................................7

5 Lasnex calculation of $x$-ray signal response from multilayer XRD, soft channel aluminum filtered XRD, given the input laser pulse................................9

6 Laser-plasma EUV source size as inferred from an $\mathrm{x}$-ray pinhole camera..................10

7 Recording configuration for angular EUV distribution measurements.....................11

8 Angular distribution of laser-generated EUV radiation....................................................12

9 Relative target volume ejected by a $0.8 \mathrm{~J}, 248 \mathrm{~nm}$ laser pulse versus the energy density required to melt the target from a solid at $20^{\circ} \mathrm{C}$, plotted for selected target materials..............................................................................14

10 EUV yield as a function of metal thickness demonstrating burn-thru depth.........16

11 Schematic diagram of Xe pellet injector experiment.....................................................17

12 Configuration for use of transmission grating spectroscopy......................................18

13 Comparison of material spectra at $2 \times 10^{11} \mathrm{~W} / \mathrm{cm}^{2}$.....................................................19

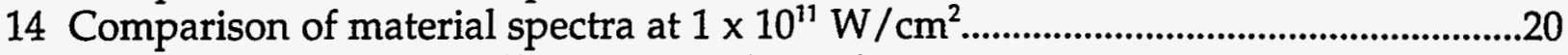

15 Measured conversion efficiencies with UV lasers...........................................................21 


\section{Summary}

Production of the 4 Gbit DRAM will require critical dimensions less than $160 \mathrm{~nm}$. Only radiation in the extreme ultraviolet (or vacuum ultraviolet, VUV) will be able to access this space. While large scale, expensive synchrotron sources can readily produce the required energy in the VUV, a laser-plasma source offers the opportunity to produce adequate energy in the sub-second times needed for stepand-repeat lithographic equipment. -Most importantly, such systems are far less expensive than a synchrotron and don't suffer from single point failures.

This LDRD performed the seminal measurements necessary to validate the laserplasma concept and to drive the design of targets, choice of laser, and the requirements for the optical condenser. Experiments were conducted with $\mathrm{KrF}$ at $0.248 \mathrm{~nm}, \mathrm{XeCl}$ at $0.308 \mathrm{~nm}$, and $\mathrm{CO}_{2}$ at $10.6 \mu \mathrm{m}$. The characteristics of the VUV laser-plasma source included conversion efficiency into the VUV, source size, source angular distribution, source spectra in the VUV, and the production of target debris. The last issue was found to be crucially important since the expensive condenser optic needed to be within $10 \mathrm{~cm}$ of the source.

Regardless of laser chosen, the conversion efficiency could be made to reach approximately $0.5 \% / \mathrm{ev}$ near $13.5 \mathrm{~nm}$ (from laser joules incident to VUV joules out). The ultraviolet lasers produced blackbody spectra with few lines, while lasers at 1.06 $\mu \mathrm{m}$ or $10.6 \mu \mathrm{m}$ produced largely spectral line sources. Debris production was far more severe with UV lasers due to absorption at far higher plasma densities. Masslimited tapes produced equivalent yields, but did not reduce debris. Material was instead released from the tapes at great distances from the focal spots because of thermal conduction. Cryogenic targets showed promise of reducing accumulated debris, and narrow targets reduced debris by limiting transverse thermal conduction. Tapes or wires could be delivered from a rapid tape drive that was developed under this program.

Angular distributions of the emitted radiation were necessary for optical condenser design. Distributions appeared to be dependent upon source size, which was in turn dependent upon laser pulselength. Short pulses (less than $15 \mathrm{~ns}$ ) yielded Lambertian sources, while longer pulses yielded sources varying more slowly with angle.

Source size was readily maintained below $150 \mu \mathrm{m}$ by limiting laser pulselength.

The results of this work demonstrated that there is sufficient VUV yield into the requisite energy band to fabricate a laser-plasma VUV stepper for sub-micron lithography. The primary issue to be solved in the future is improved target design 
to limit debris and thus to minimize maintenance times. Source geometry was fully consistent with conventional optical designs to complete the design of the stepper. 


\section{Initial Development of Efficient, Low-Debris Laser Targets for the Sandia Soft X-ray Projection Lithography Effort}

\section{Introduction}

Laser-plasma sources of extreme ultraviolet radiation (EUV) offer small footprint, reliable short-wavelength lamps for use in producing $0.1 \mathrm{~mm}$ design rules in integrated circuit lithographic processing. The key is to achieve high $x$-ray yield with a small source that produces no debris. ${ }^{1-4}$ Yield has been improving by use of appropriate targets with laser parameters conducive to producing a limited plasma expansion. Debris, however, continues to be a severe problem, threatening the multilayer-coated surface of the condenser optics close to the target.

Developmental targets have included bulk solid metals, ceramics, cryogenic solids, and thin films. The present spectral region of interest $(\sim 13.5 \mathrm{~nm})$ has been chosen both by the characteristic spectral yields of convenient materials and by the high reflectivity possible with $\mathrm{Mo} / \mathrm{Si}$ multilayer mirrors as one approaches the silicon Ledge at $12.5 \mathrm{~nm}$. All data on conversion efficiency (CE) was performed with biplanar $x$-ray photodiodes, six with broadband filters and one with a multilayer pre-mirror that provided a $10 \%$ bandpass at $14.2 \mathrm{~nm}$.

Most experiments were performed using the KrF Laser Plasma Source (LPS) at Sandia/California providing $1 \mathrm{~J}$ in $32 \mathrm{~ns}$ at $248 \mathrm{~nm}$ at a repetition rate of up to 100 $\mathrm{Hz}$. Intensities varied from 1.4-2.8 $\times 10^{11} \mathrm{~W} / \mathrm{cm}^{2}$ and targets consisted of solid $\mathrm{Au}$, $\mathrm{Sn}, \mathrm{W}, \mathrm{Ta}, \mathrm{Cu}$, and $\mathrm{Cu}$-on-mylar. Additional experiments were conducted at Jamar Technology Inc., where they provided a compact $\mathrm{XeCl}$ laser at $308 \mathrm{~nm}$. The laser pulse at Jamar was shortened to yield a $4.5 \mathrm{~ns}$ time history with approximately 0.4 $\mathrm{J} /$ pulse, providing intensities of $2-6 \times 10^{11} \mathrm{~W} / \mathrm{cm} 2$ on target. Laser focal spot size was maintained at $125 \mathrm{~mm}$ diameter with the LPS and $90 \times 135 \mathrm{~mm}$ with the $\mathrm{XeCl}$ laser. Additional experiments were attempted with a $4 \mathrm{~ns} \mathrm{CO}_{2}$ laser at $10.6 \mathrm{~mm}$ at the University of Laval, Quebec, Canada. Laser intensities were $0.1-1 \times 10^{10} \mathrm{~W} / \mathrm{cm}^{2}$, due to a large focal spot and because equivalent conversion efficiency into the EUV occurs at lower intensities for longer wavelengths.

Our target chamber operated in the low 10-5 Torr range and included a target drum of $3^{\prime \prime}$ diameter which contained either gold in a .012" plating on stainless steel or thick sheet targets of other materials. Diagnostics included a six channel filtered $x-$ ray diode array, the multilayer $x$-ray diode, a soft $x$-ray pinhole camera filtered with 1 $\mu \mathrm{m} \mathrm{Be}$, a similarly filtered photographic plate capable of recording the angular distribution of the emitted $x$-rays, a 5000 lpmm transmission grating spectrograph, and detectors for laser energy and pulseshape monitoring. 


\section{Laser-Plasma Source Characterization}

Our working group conceived and developed thin-film metal-coated targets and cryogenic targets, in addition to thick solid targets as candidate lithographic VUV sources. We studied the impact of wavelength and pulselength on $C E$, source size, and debris and concluded that thin-film targets could offer a continuously replenished source (via a large tape drive), Extensive measurements showed that $\mathrm{CE}$ could reach $2 \%$ within the spectral acceptance region of the multilayer optics, and that source size was purely dependent upon laser pulselength.

Conversion efficiency varied little with wavelength from $248 \mathrm{~nm}$ to $1.06 \mu \mathrm{m}$. However, the radiation physics was quite different. Long wavelength lasers stimulated line radiation and could produce spectrally brighter sources than short wavelength lasers, which produce primarily Planckian sources. Yet within the bandpass constraints of practical multilayer mirror optics, comparable spectral brightness was achievable with all laser wavelengths examined. Typical maximum $C^{\prime} E^{\prime} s$ were found to be $0.5 \% / \mathrm{eV}$ of the incident laser energy into the 89 to $95 \mathrm{eV}$ region.

LASNEX was used to simulate and predict CE's and plasma source size with various pulse lengths and shapes. Extensive comparison was made with experimental data obtained using $32 \mathrm{~ns}$ and $4.5 \mathrm{~ns}$ Gaussian pulses at $248 \mathrm{~nm}$ and $308 \mathrm{~nm}$, respectively. The code accurately predicted $\mathrm{x}$-ray yields and $\mathrm{x}$-ray spot sizes, giving us confidence to use these results to predict yield scaling with pulseshape and to estimate the effects of varying pulseshapes.

Source diameter varied from $300 \mu \mathrm{m}$ down to $80 \mu \mathrm{m}$, and was primarily dependent upon laser pulselength. While focal spot size determined two of the final EUV spot dimensions, pulselength determined how far the plasma source would evolve from the target surface before the laser would turn off. The EUV optics required a spot size less than $150 \mu \mathrm{m}$, which we showed was readily achievable.

We also measured EUV angular distribution and found that it varied as a Lambertian for the smallest $x$-ray source, and as $\cos ^{0.7} \theta$ for the largest $x$-ray source.

Debris remained the most significant problem to solve to permit use of a laserplasma x-ray source. Debris was compared for solid targets and thin-foil targets. Preliminary comparison is now underway with cryogenic targets. Thin foil targets offered little improvement over solids. Cryogenic targets may produce significant initial debris, but the particulates will rapidly sublime, leaving no permanent coverage over mirrors. Thus the tape-drive-mounted target became the standard. Work is continuing under other funding. 
Active debris mitigation techniques were designed and examined, including mechanical choppers, gas puffs, and magnetic deflection. The latter had no effect and gas puffs had marginal success. A mechanical chopper was built and has reduced debris by factors of ten or more. However, debris velocities proved to be high enough to require extremely high rotational chopper speeds. The chopper has been redesigned to handle these high $\mathrm{rpm}$.

\section{Conversion Efficiency}

Conversion efficiency (CE) and laser average power directly affect wafer throughput on a projection $x$-ray lithography system. We measured conversion efficiency on six metal targets, each of a thickness exceeding $100 \mu \mathrm{m}$. These included $\mathrm{Fe}, \mathrm{Sn}, \mathrm{Ta}, \mathrm{Au}$, $\mathrm{Pb}$, and $\mathrm{W}$. Experiments were performed with the Sandia Laser Plasma Source, a Lambda Physik KrF laser operating at $248 \mathrm{~nm}$ with $1.2 \mathrm{~J} /$ pulse of nominal $32 \mathrm{~ns}$ FWHM. These scanned intensities from $0.7-2.8 \times 10^{11} \mathrm{~W} / \mathrm{cm}^{2}$. Another experiment was performed at Jamar Technologies Inc. using their compact $\mathrm{XeCl}$ laser which produced $1.5 \mathrm{~J} /$ pulse with a $47 \mathrm{~ns}$ pulse at $308 \mathrm{~nm}$. The Jamar work covered these same elements, except for lead.

The results demonstrated a $\mathrm{CE}$ that peaked in the region of $\mathrm{Ta}$ and $\mathrm{Au}$, and that increased with laser intensity (Figures 1,15). In simulations reported later in this article, $\mathrm{CE}$ appeared to peak in the low $10^{11} \mathrm{~W} / \mathrm{cm}^{2}$ region. This was supported by the experiments of Kauffman et al. at Lawrence Livermore National Laboratory, which studied intensities up to $2 \times 10^{12} \mathrm{~W} / \mathrm{cm}^{2} .5,6$

The choice of these six materials was based upon the work of Bridges et al., which showed the uncalibrated VUV spectra of many elements.' We made no attempt to scan through the $M-, N$-, or O-shells of many different atomic numbers. Instead our choice of six were the best expected radiators in the $13.9 \mathrm{~nm}$ region.

$X$-ray Diode (XRD) traces in the band of interest consistently showed pulses that began 7-9 ns after the laser hit the target, and that turned off with a FWHM of only 19-20 ns. This was true during both $\mathrm{KrF}$ and $\mathrm{XeCl}$ irradiation, for all intensity conditions, and for all target materials. The multilayer-XRD represented the 13.9 $\mathrm{nm}$ radiation time history and suggested techniques for improving the conversion history by modifying the laser pulselength as will be seen in section $\mathrm{V}$. The long pulse of the XeCl laser produced the same multilayer-XRD FWHM as the KrFproduced soft $x$-ray signal. Figure 1 summarizes the results of conversion efficiency measurements made on solid targets of various $\mathrm{Z}$ with $\mathrm{KrF}$ and $\mathrm{XeCl}$ lasers at 248 $\mathrm{nm}$ and $308 \mathrm{~nm}$, respectively. The results demonstrate that peak CE is comparable to that attainable with a YAG laser on similar targets. The authors acknowledge that YAG illuminated tin targets are capable of twice the bandlimited emission via line production at $13.5 \mathrm{~nm}$. The tin target is however of little practical value in an EUVL system, because of tin's enormous debris production. 
Continuous measurements of soft $x$-rays were possible with a variety of techniques including $x$-ray diodes ${ }^{8}$, phosphors ${ }^{9}$, low dead-layer silicon diodes ${ }^{10}$, and channel electron multipliers ${ }^{11}$. Aluminum photocathode $x$-ray diodes offered fourteen years of history in the field and could readily be calibrated with CD x-ray tube sources and with synchrotrons. Uncertainties in the calibrations and surface changes over time resulted in $\pm 30 \%$ error bars on all reported XRD data.

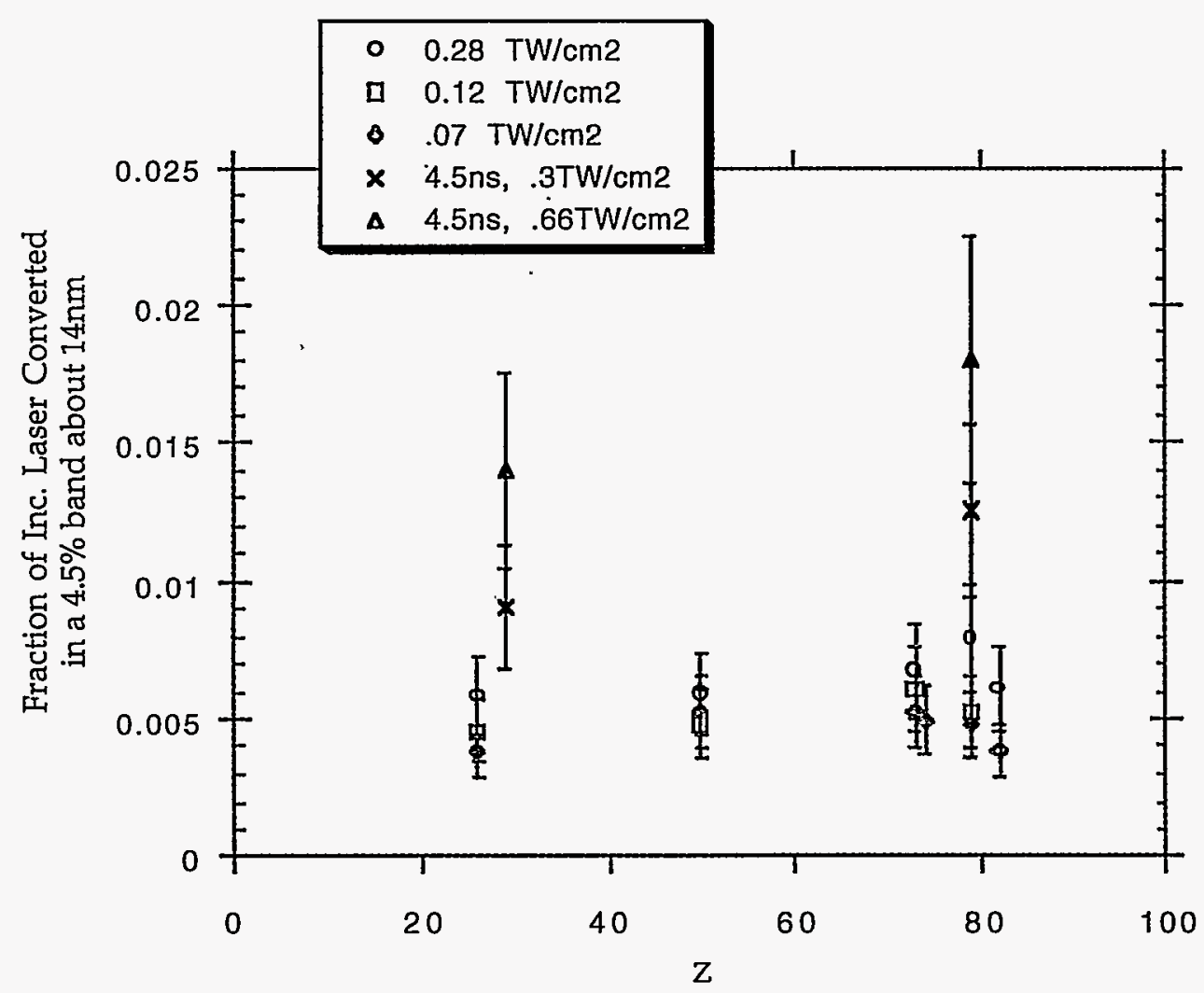

Figure 1. Conversion Efficiency for $248 \mathrm{~nm}$ and $308 \mathrm{~nm}$ light into the VUV with 32 ns and 4.5 ns pulses, respectively

We utilized an array of five absolutely calibrated, broadband, filtered $x$-ray diodes to measure the emitted $x$-ray spectrum from our laser-plasmas. (Due to the broadband nature of such XRD's, narrow line emissions were not directly observed, but were averaged into the broad, largely blackbody spectrum.) The diode array was compact, built onto a $2.5^{\prime \prime}$ diameter conflat flange and was supplied by KMS Fusion Inc. The individual channel responses are shown in Figure 2. An additional narrowband XRD consisted of a flat multilayer x-ray mirror from Ovonyx Synthetic Materials Inc. coupled to a $1 \mu \mathrm{m}$ beryllium-filtered $\mathrm{x}$-ray diode. This produced a channel with a $10 \%$ bandwidth ábout $13.9 \mathrm{~nm}$. The x-ray mirror was calibrated at AT\&T Bell Labs, Murray Hill, NJ, while the XRD photocathode calibrations were performed at EG\&G/Atlas, Las Vegas, NV. 
All XRD's were operated at a high enough voltage to provide subnanosecond resolution. Signals from each channel were recorded on either fast oscilloscopes or on transient digitizers. X-ray spectra in the $70-300 \mathrm{eV}$ region were then reconstructed by unfolding the data, based upon the calibrated instrument response functions. That portion of the spectrum falling under the $4.5 \%$ band at $13.9 \mathrm{~nm}$ thus constituted the relevant converted $x$-ray source: These values were then compared against the multilayer-XRD dosimeter, as well as against the signal collected in the 1 $\mathrm{mm}$ beryllium-filtered XRD.
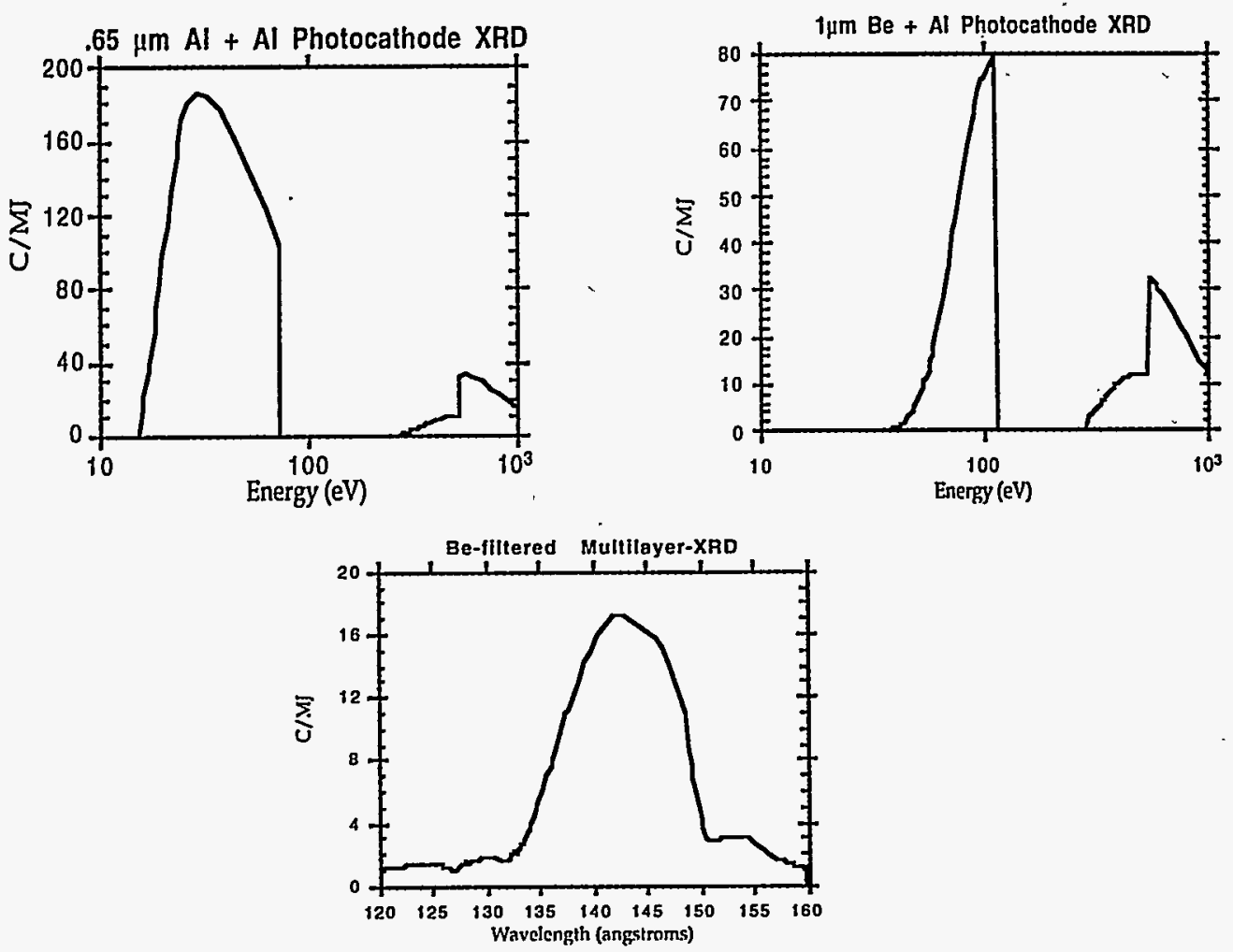

Figure 2. Spectral response curves for three of the four $\mathrm{x}$-ray diode units

The laser intensity on target was directly measured by recording the far field pattern on high resolution UV-sensitive photographic.plates (Kodak SA-1). Densitometer scans of the plates were then run through film D-log-E curves to infer intensity as a function of position. Two optics were used for these experiments with a focal length of $50 \mathrm{~cm}$ and $100 \mathrm{~cm}$ respectively. The former produced a focal spot of $110 \mu \mathrm{m}$ in diameter, while the latter yielded a $225 \mu \mathrm{m}$ spot. Each also showed $\sim 30 \%$ of the laser energy spread out into low-intensity wings extending some $1 \mathrm{~mm}$ from the focal spot. ${ }^{1}$

Past work with LASNEX simulations of our laser plasma source indicated that short pulses (<15 ns) provide a higher fractional conversion of laser light into $13.9 \mathrm{~nm}$ 
light. In addition we observed that the $\mathrm{x}$-ray temporal history with $32 \mathrm{~ns}$ laser pulses was much shorter than the laser pulse, as if the plasma were "shuttering" the radiation emitted from the absorption region. Similar observations had not been seen with $0.53 \mu \mathrm{m}$ or $1.06 \mu \mathrm{m}$ light at shorter pulselengths at Lawrence Livermore National Laboratories. ${ }^{6}$

We studied the effect of changing the pulselength, while keeping laser wavelength and intensity roughly constant at Jamar Technology Inc. The Jamar $\mathrm{XeCl}$ laser was used to amplify a chopped $4.5 \mathrm{~ns}$ pulse. Energy and pulseshape were monitored regularly. The data showed roughly a factor of two increase in conversion efficiency over similar intensities at $45 \mathrm{~ns}$. Targets of $\mathrm{Au}, \mathrm{Sn}, \mathrm{Cu}$, and $\mathrm{Cu}$-on-mylar all showed significant increases in yield.

Figure 3 suggests the reason for the observed increases in $x$-ray conversion efficiency. These are the spectra as recorded on our six channel broadband $x$-ray diode array. The high energy cutoffs for each channel are $\mathrm{Al}-70 \mathrm{eV}, \mathrm{Be}-108 \mathrm{eV}$, Parylene N-282 eV with the multilayer XRD peaked at $14.2 \mathrm{~nm}$. Note that the Jamar spectrum is far hotter than the 32 ns LPS spectrum, as indicated by the fact that the Be channel far exceeds the Al channel with the short pulse input. The multilayer XRD is comparably higher for shorter pulses. Pinhole photographs showed a pillbox shaped radiator with its thin side facing the laser. The short pulse permitted little expansion, permitting the detectors to more directly observe the hot absorption region. Less plasma obscured our view, and no shuttering took place.
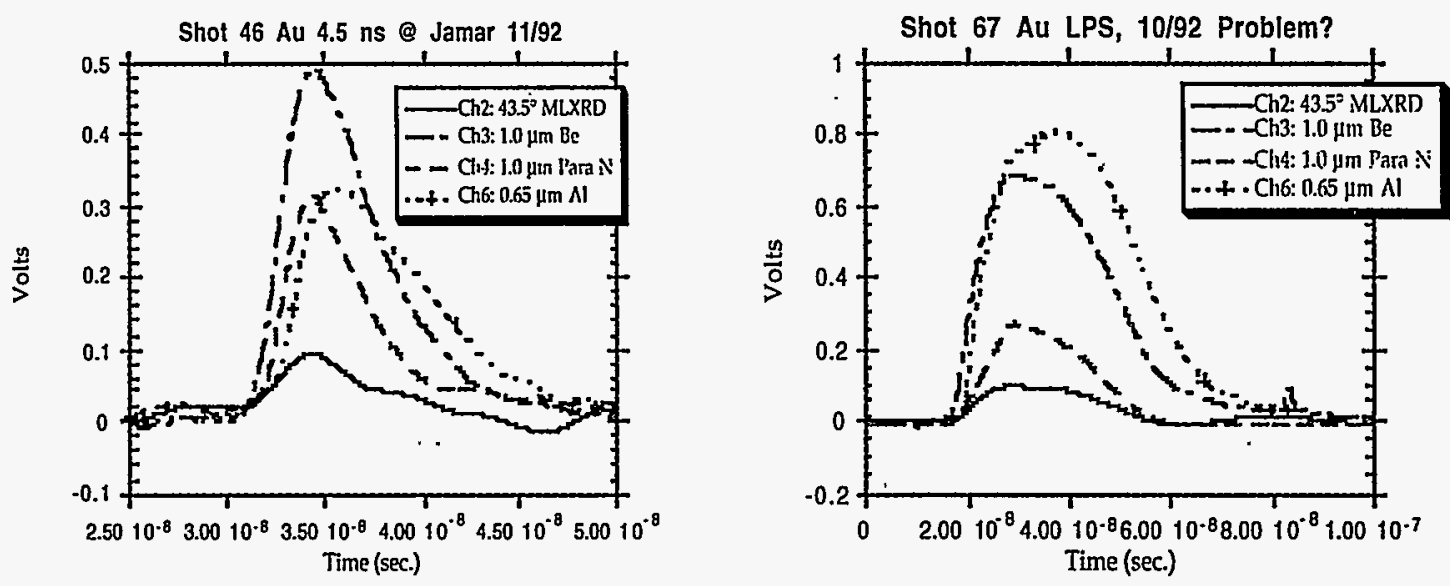

Figure 3. X-ray Diode Signals from short and long pulse excimer laser-plasmas, showing the higher temperature obtained at shorter pulselengths

Studies reported at $1.06 \mu \mathrm{m}$ had indicated that equivalent $C E$ was obtained at lower intensities than at UV wavelengths by almost an order of magnitude. ${ }^{12}$ This motivated us to study the conversion process of a very long wavelength laser, the $\mathrm{CO}_{2}$ laser at $10.6 \mu \mathrm{m}$. A $4 \mathrm{~ns} 1 \mathrm{~J} \mathrm{CO}_{2}$ system was utilized at the University of Laval in 
Quebec, Canada in the laboratory of Prof. S. L. Chin. The focal spot was poor due to large wings on the beam, resulting in only $30 \%$ of the energy being contained in a $550 \mathrm{~mm}$ diameter, the rest residing in a $1.3 \mathrm{~mm}$ diameter.

As expected the plasma temperature was quite high considering the low intensity. Figure 4 shows that the temperature in the $\mathrm{CO}_{2}$ 'generated plasma was higher than that seen in the $\mathrm{XeCl}$ generated plasma. The $\mathrm{CE}$ calculated from the left figure was virtually identical to that obtained from the $\mathrm{XeCl}$ data of the right figure i.e. $0.5 \% / \mathrm{eV}$ at $14.2 \mathrm{~nm}$. Yet the $\mathrm{CO}_{2}$ intensity was 100 times less than the $\mathrm{XeCl}$ intensity! Since the ideal focal spot for the imaging optics was $\sim 150 \mu \mathrm{m}$, this would suggest that a $\mathrm{CO}_{2}$ system would have to operate at an extremely high rep rate with little energy per shot. Debris quantity was similar to that obtained with UV wavelengths, but the size distribution was clearly skewed towards sub-10 micron particles with the long wavelength light.
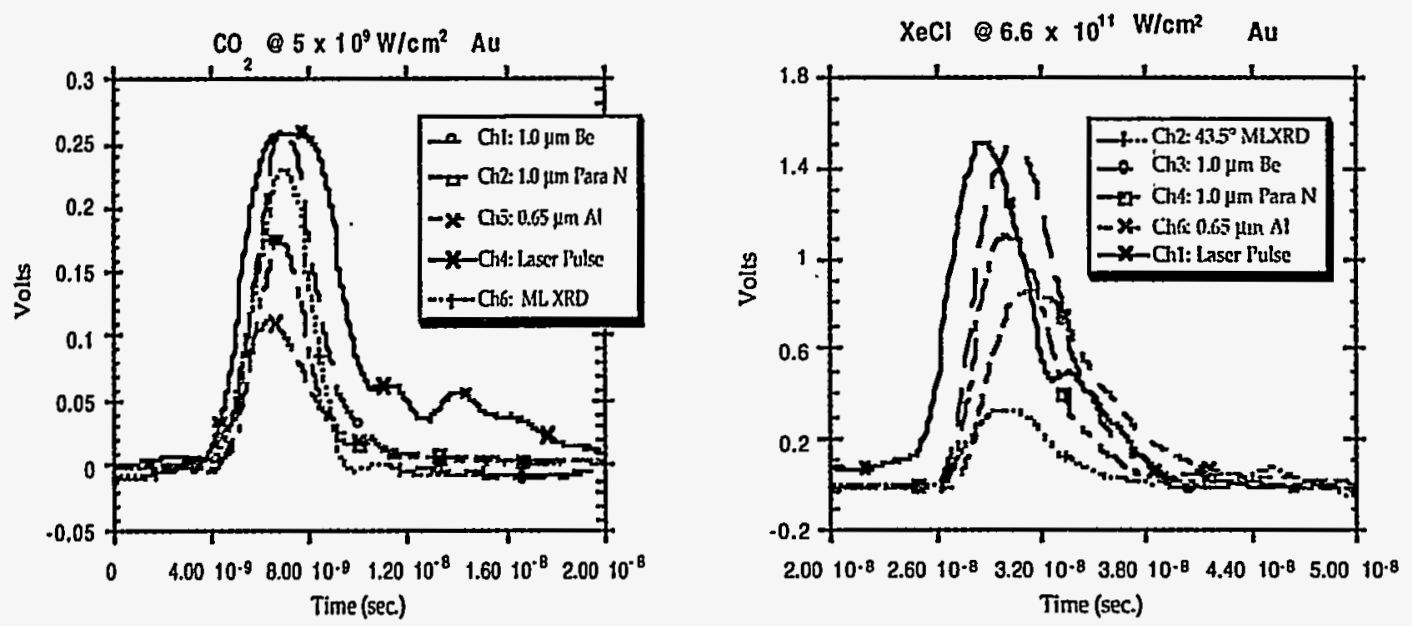

Figure 4. Comparison of $\mathrm{X}$-ray Diode data between a $\mathrm{CO}_{2}$ laser-plasma and a $\mathrm{XeCl}$ laser-plasma, showing high temperatures and equivalent conversion efficiencies at dramatically different intensities

All x-ray pulses were approximately $80 \%$ of the laser pulsewidth, indicating the possible operation of some shuttering mechanism.

\section{"Hydrodynamic simulations}

Much of the data regarding absolute conversion efficiency and $x$-ray time history were compared with LASNEX/TDG simulations in an effort to improve our understanding of the laser-to- $X$-ray conversion process. LASNEX is a twodimensional Lagrangian radiation hydrodynamics code used extensively in the inertial confinement fusion program at Lawrence Livermore National Laboratory, Los Alamos National Laboratory, and Sandia National Laboratories. TDG is a 
LASNEX postprocessor that is routinely used to predict the response of diagnostics such as XRD's and $X$-ray pinhole cameras.

As input for the LASNEX simulations, we used a experimentally determined laser power time history and Gaussian spatial intensity profile with normal incidence on a disk target (i.e. the 2D LASNEX calculation assumes the target to be rotationally symmetric about the axis of the laser beam). An equal ratio zoning scheme (finer zones near the target surface and laser spot center) was used in the target material. Radiation transport was performed via multigroup diffusion with a relatively course photon binning over a 0.1 to $5000 \mathrm{eV}$ range and a fine group structure within the $80-100 \mathrm{eV}$ range of interest in this problem. A non-LTE average atom approximation (using the XSN code) was used in-line with LASNEX to compute zone-by-zone electron densities, level populations, and multi-group opacities. The time-dependent LASNEX output was combined with experimentally determined filtered $X R D$ response functions and experimental $x$-ray detector geometry (i.e. distance from the target, focal spot size, angle from the laser axis) as input to the TDG postprocessor. The TDG output includes predictions of the amps vs. time output signal for each of the filtered XRD channels. Al, Be, parylene $\mathrm{N}$, and parylene $\mathrm{D}$ transmissions were simulated.

Typical LASNEX/TDG predictions for the Be and Al filtered XRD's are shown overlaid with the laser input power history in Figure 5. In this particular calculation the laser has a FWHM of $38 \mathrm{~ns}$ and delivers $1.2 \mathrm{~J}$ within a $220 \mathrm{~mm}$ diameter spot. Notable features include the predictions of a "shuttering effect" for the Be-filtered XRD (its FWHM is only $27 \mathrm{~ns}$ ) and an XRD turn-on delay of 5-10 ns for all channels. These features are in agreement with the experimental observations. The predicted overall efficiency of conversion into $87-91 \mathrm{eV}(4.5 \%$ band about $13.9 \mathrm{~nm}$ ) $x$-rays is $0.75 \%$. Upon examining the LASNEX output, we find that the shuttering of the Be-filtered XRD is a fairly complicated effect that appears to be primarily due to the development of a plume of relatively cool plasma that becomes opaque to the $87-91 \mathrm{eV}$ x-rays. Output of the Al-filtered XRD, on the other hand, exceeds the FWHM of the laser pulse since it is responding primarily to the 20-70 $\mathrm{eV}$ x-ray of the cool plume. 


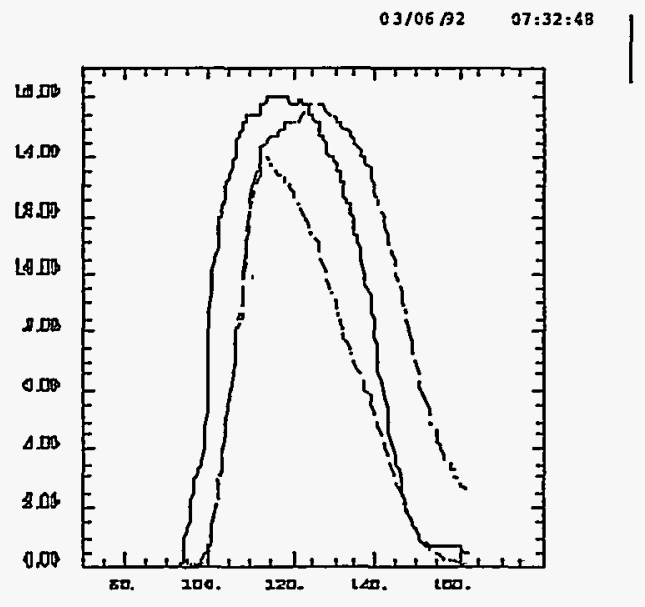

Figure 5. Lasnex calculation of $x$-ray signal response from multilayer XRD (dashed), soft channel aluminum filtered XRD (dash-dot), given input laser pulse (solid line)

This situation suggests that a decrease in laser pulse length might result in an increase in conversion efficiency into the $87-91 \mathrm{eV}$ band. Presumably, with the shorter pulse length (at a given intensity) the cool plume plasma would not have enough time to obscure the hot spot during the time of the laser pulse. The LASNEX/TDG calculations support this conjecture. If the laser pulse is cut to $10 \mathrm{ns,}$ the efficiency improves to $1.2 \%$, but the Be channel cutoff is due to the laser power cutoff, suggesting that the laser pulselength is too short. The $20 \mathrm{~ns}$ laser pulse simulation predicts a Be channel response that closely follows the tail of the laser pulse resulting in a further improvement in efficiency of $\sim 1.6 \%$ into the $87-91 \mathrm{eV}$ band.

Once might also suspect a relationship between laser intensity and $\mathrm{CE}$. Our LASNEX calculations also tend to support this speculation. LASNEX-calculated CE for a $20 \mathrm{~ns}$ laser pulse is predicted to increase from $1.6 \%$ to $1.8 \%$ if the laser spot size is decreased from $220 \mu \mathrm{m}$ to $110 \mu \mathrm{m}$. A further increase in CE to $1.9 \%$ is predicted for 
an $80 \mathrm{~mm}$ diameter spot, and such increases appear to saturate here at an intensity of $6 \times 10^{11} \mathrm{~W} / \mathrm{cm}^{2}$.

\section{Source Size}

Knowledge of source size was mandatory in order to estimate the amount of light that could be collected in a given optical relay system. Present designs of condensers and imaging optics recommended a source size that was less than $150 \mathrm{~mm}$ along the plane formed by the laser and lithographic optic axis. In order to measure the extent of our laser-plasma sources we designed an x-ray pinhole camera, filtered by $1 \mathrm{~mm}$ Be and using Kodak SA-1 plates for recording. A $50 \mu \mathrm{m}$ diameter pinhole was used, providing limited resolution, but staying well above the limits for diffraction, which begin to affect image quality at $34 \mu \mathrm{m}$ at our $13.9 \mathrm{~nm}$ wavelength. Pinhole-to-source distance was approximately $3.8 \mathrm{~cm}$ with a magnification of 14.8:1.

The beryllium filter and the overcoated film provided a detected spectrum peaking at about $100 \mathrm{eV}(12.4 \mathrm{~nm})$ with a breadth of roughly $+8 \mathrm{eV},-20 \mathrm{eV}$. This placed the image in the relevant spectral region and assured its validity for use in predicting optical collecting efficiency of the multilayer coated condenser. Pinhole images were recorded, digitized, and compared to LASNEX TDG simulations of the radiating: source size and gave very similar results.

The data from several experiments are shown in Figure 6. The lowest intensity data were recorded using a $100 \mathrm{~cm}$ focal length lens and a $32 \mathrm{~ns}$ pulse (laser focal diameter of $250 \mu \mathrm{m}$ ); the middle intensity used a $50 \mathrm{~cm}$ lens and a $32 \mathrm{~ns}$ pulse (laser focal diameter of $125 \mu \mathrm{m}$ ); and the highest intensity used a $40 \mathrm{~cm}$ lens and a $4.5 \mathrm{~ns}$ pulse (laser focal diameter of $200 \mu \mathrm{m}$ ). One hundred $\mathrm{eV}$ sources appear to be larger than the laser

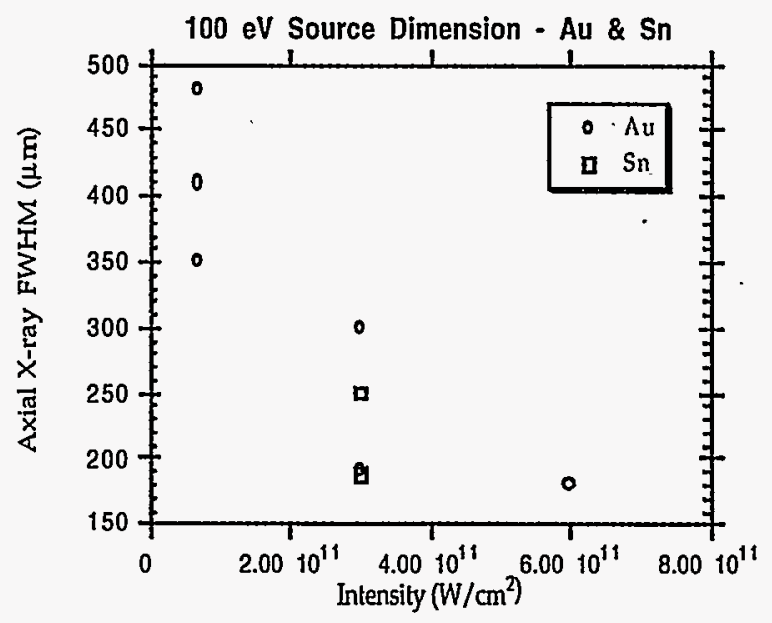


Figure 6. Laser-plasma EUV source size as inferred from an x-ray pinhole camera

focal spot for long pulses, and comparable to the laser spot size for short pulses. Since we are measuring the source size in the direction of the plasma expansion, this is simply an indication of the time permitted for such an expansion to take place. Also note that we have not yet achieved the small focal spot that is desired for optimum x-ray collection, but we clearly have the tools to achieve such a spot.

As an aside, one did not simply want to decrease the laser focal spot to achieve a small $x$-ray source size. Decreasing the laser spot size would increase the laser intensity on target, resulting in a larger production of debris. The $150 \mu \mathrm{m}$ dimension was already a compromise between conversion efficiency, debris, and collection efficiency.

\section{Angular Distribution}

The collection efficiency of the soft $x$-ray projection imaging optics is directly affected by the angular distribution of the emitted radiation in the relevant band. Early work by several authors had indicated that EUV radiation from low intensity laser plasmas was emitted with little azimuthal variation, and had measured distributions varying from $\cos ^{0.3} \theta-\cos \theta .^{2-4}$

We implemented a photographic scheme to measure the Angular $X$-ray Emission of our discharge-laser-produced plasma sources. A photographic Kodak SA-1 or Ilford $Q$ plate was placed between the angles of $35^{\circ}-85^{\circ}$, filtered by $1 \mu \mathrm{m}$ Be to record single shot distributions. Figure 7 is a schematic of the geometry of this recording system. The $x$-ray films had been calibrated for a relative D-log E response so that data could be converted from density on film to relative incident EUV intensity in the 80-108 $\mathrm{eV}$ range.

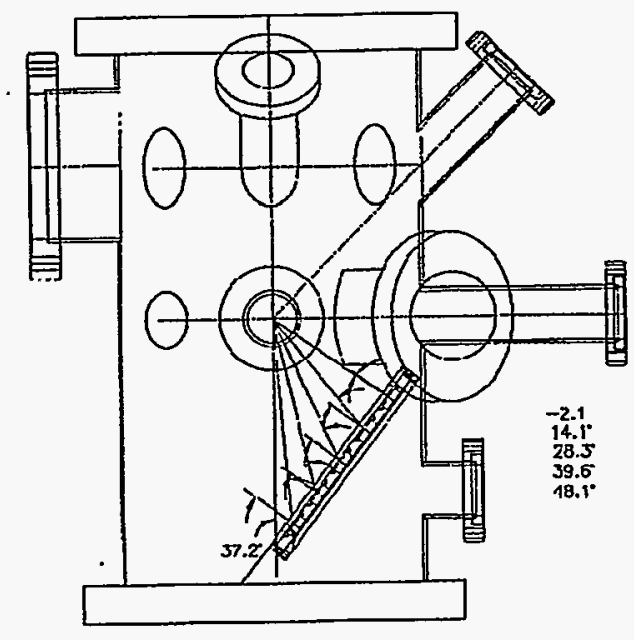

Figure 7. Recording configuration for angular EUV distribution measurements 
The results of these exposures is shown in Figure 8. Note the different distributions obtained with two different focal spot sizes and durations, which are the result of 1) having a bulk radiator rather than a surface radiator and 2) the great difference in the sizes of these two sources. The LPS produced a $32 \mathrm{~ns}$ long expansion of the plasma from the target surface, producing a three-dimensional source that was approximately a cylinder $300 \mu \mathrm{m}$ in diameter by $500 \mu \mathrm{m}$ long. On the other hand, the $\mathrm{XeCl}$ laser produced a pillbox-like VUV source that was $200 \mu \mathrm{m}$ in diameter, but only $80 \mu \mathrm{m}$ tall. This latter dimension was due to the comparatively short $4.5 \mathrm{~ns}$ duration, during which the plasma could only expand a short distance from the target surface.

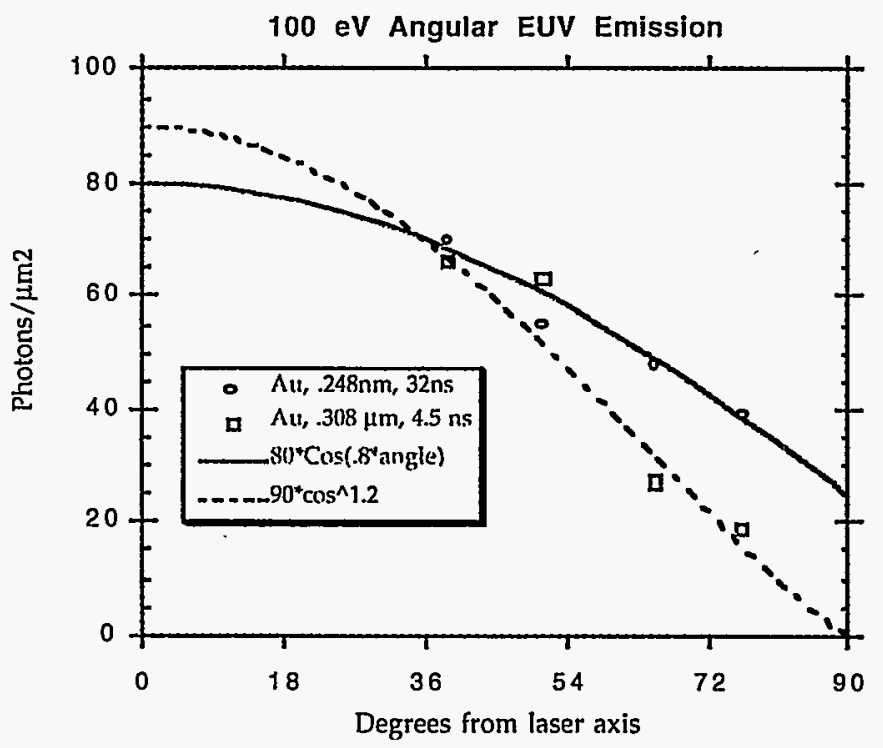

Figure 8. Angular distribution of laser-generated EUV radiation

Note the broad cos $.8 v$ angular distribution that appears with our larger source from the $\mathrm{KrF}$ generated source. This source would require a large $\mathrm{f} / \#$ condenser to collect all the light. However, the smaller source produced by the short pulse $\mathrm{XeCl}$ system resulted in a pure Lambertian source, falling off as $\cos \vartheta$. Here more of the EUV light is forward directed, relaxing requirements on the condenser and on the other imaging optics down the lithographic line.

\section{Debris}

The production of laser-plasma EUV radiation sufficient for commercial lithography was clearly established during this LDRD. However, the viability of this source rested not purely upon its optical characteristics, but also perilously upon its physical, debris-generating characteristics. Any material struck by a high-intensity 
laser received a shock produced by the rapid, local temperature rise in the target medium, be it solid, liquid, or gas. This shock inevitably resulted in the release of minute bullets of heated target material, occurring microseconds after the laser had terminated.

\section{Production of Plasma Source Ejecta}

Solid bulk metal targets have long been known to eject both atomic vapor and microscopic particulates, each phase having characteristic velocity and angular distributions. We have measured the total mass ejected from semi-infinite solid targets of $\mathrm{Fe}, \mathrm{Cu}, \mathrm{Sn}, \mathrm{W}, \mathrm{Ta}, \mathrm{Mo}$, Au under $0.8 \mathrm{~J}$ laser illumination at an intensity of $2 \times 10^{11} \mathrm{~W} / \mathrm{cm}^{2}$. Experiments were performed by measuring the total mass lost from each target after exposure to several thousand laser pulses in vacuum. Each laser pulse was focused onto a previously unexposed region of the target, to avoid increases in ejection rate caused by craters produced from previous laser pulses. No provisions were made to spatially filter the focused excimer beam to remove weakly focused contributions to the incident energy from amplified spontaneous emission. Fig. 8 plots the relative volume of ejected target material versus the energy density required to drive each material from a solid at room temperature to a liquid at its melting point, defined as

$E_{\text {melt }}=\left[\left(T_{m e l t}-T_{0}\right) C_{p}+D_{f}\right] r$

where $T_{\text {melt }}$ is the melting temperature, $T_{0}$ is the initial temperature, $C_{p}$ is the specific heat, $\mathrm{DH}_{\mathrm{f}}$ is the heat of fusion and $\mathrm{r}$ is the density. As can be seen, the laserejected target volume is approximately proportional to $\left(E_{m e l t}\right)^{-1}$. While this result is intuitively reasonable, the relationship should be regarded as only approximate, given the wide range of grain size, purity and microscopic surface morphology of the samples employed. Melting, and not fracture, did appear to be the dominant mechanism of particulate production, as inferred from SEM observations of both the target craters and the deposits formed on nearby substrates. These revealed previously molten features only, with no fractured features visible. Fig. 8 also shows that $\mathrm{Sn}$ targets generate 15 times more ejecta than refractory materials such as $\mathrm{W}$ and $\mathrm{Ta}$. As reported above, the conversion efficiency into a $4.5 \%$ bandwidth centered at $14 \mathrm{~nm}$ for $\mathrm{Sn}, \mathrm{Ta}$, and $\mathrm{W}$ were all approximately $0.5 \%$ at an intensity of 7 $x 10^{10} \mathrm{~W} / \mathrm{cm}^{2}$. Thus, Ta and $\mathrm{W}$ are superior to $\mathrm{Sn}, \mathrm{Au}$, or $\mathrm{Cu}$ target materials when judged solely by the ratio of soft $x$-ray flux to target ejecta. 


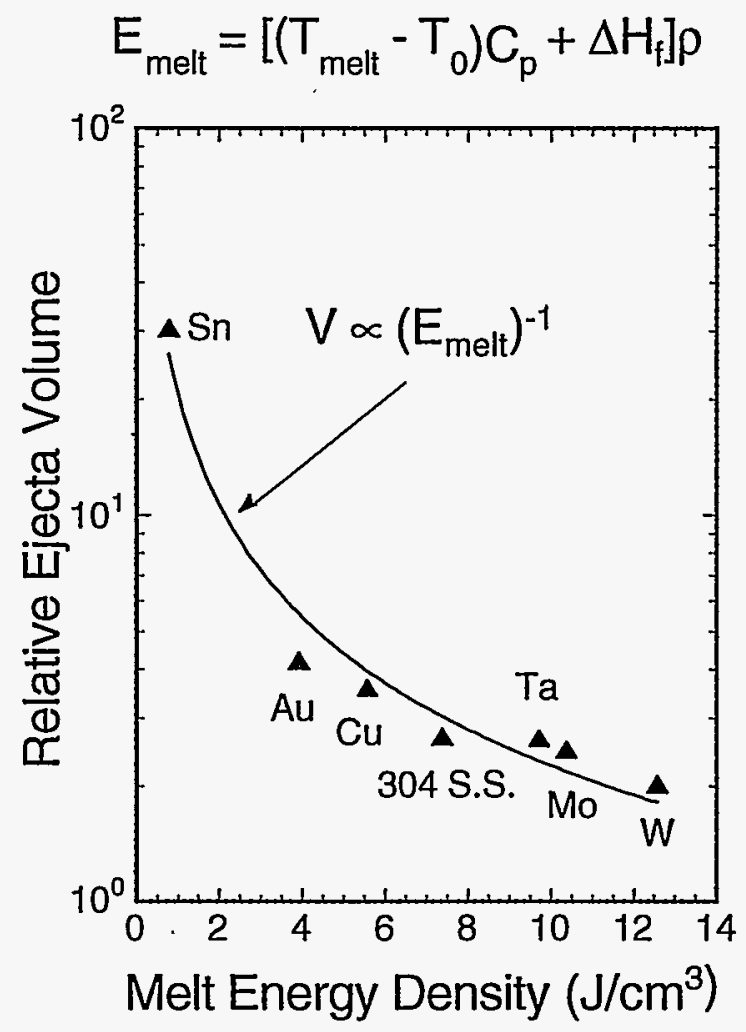

Figure 9. Relative target volume ejected by a $0.8 \mathrm{~J}, 248 \mathrm{~nm}$ laser pulse versus the energy density required to melt the target from a solid at $20^{\circ} \mathrm{C}$, plotted for selected target materials.

\section{Suppression of Target Ejecta}

Gas flows have been studied as a method to intercept target ejecta before it strikes multilayer-coated optics[1,3,7]. A difficulty with this approach was that even low-atomic-number gases such as $\mathrm{He}$ and $\mathrm{H}_{2}$, strongly absorbed $\mathrm{x}$-rays near $14 \mathrm{~nm}$. Thus, the product of gas density times the illumination path length must be kept small to minimize absorption losses. For example, the use of 200 mTorr of He has been shown to reduce the deposition of atomic vapor from laser plasma targets by a factor of $\sim 100$ [7], yielding an acceptable $50 \%$ transmittance for $13.5 \mathrm{~nm}$ radiation over a $200 \mathrm{~cm}$ path length. Unfortunately, the use of such low He pressure did little to reduce the deposition of particulate debris. For example, even in the presence of 220 mTorr of flowing He, the peak reflectance of a Mo/Si multilayer mirror located $25 \mathrm{~cm}$ from a Au plasma source was reduced by $32 \%$ after 630,000 laser pulses. While it has been shown that $1 \mathrm{~atm}$ of flowing He can significantly reduce the deposition of particulate debris onto nearby substrates [3], this method was not directly applicable to wavelengths near $14 \mathrm{~nm}$. For example, using atomic mass 
absorption coefficients for $\mathrm{He}$ at $13.5 \mathrm{~nm}, 1 \mathrm{~atm}$ of $\mathrm{He}$ would transmit only $1 \%$ over a $4 \mathrm{~mm}$ path length.

\section{Effects of Target Ejecta}

Particulate ejecta generated by Au targets under vacuum or in the presence of 220 mTorr of He could cause significant damage to nearby multilayers and other substrates. We have found that $1-10 \mu \mathrm{m}$ molten Au droplets caused cracking and adhesion failure in $\sim 1500 \AA$-thick Mo/Si multilayer coatings placed $25 \mathrm{~cm}$ from the plasma source in the presence of 220 mTorr of He. Scanning electron micrographs (SEM) revealed solidified Au droplets deposited on such multilayer coatings. These Au particulates were subsequently removed from the coating by dissolution in a commercial buffered $\mathrm{KCN}$ solution. After this treatment, SEMs revealed regions which had cracked and suffered adhesion failure due to the impact of a molten $\mathrm{Au}$ droplet. A more dramatic example was the $0.8-\AA$ / $/$ plasma shot erosion rate of a crystalline $\mathrm{Si}$ substrate placed in vacuum $2.7 \mathrm{~cm}$ from the Au plasma. Thus, although chemical etching could be used to remove $\mathrm{Au}$ and other target debris from $\mathrm{Mo} / \mathrm{Si}$ multilayer coatings, the damage from such debris was irreversible.

\section{Debris Mitigation}

A high velocity rotating shutter was devised to operate at $12000 \mathrm{rpm}$ with narrow slit shutters and an 4 inch long blade. This reduced debris by factors of 10 from solid targets, but the solid target debris was so high that it required a reduction of $10^{6}$, not just 10 for commercial application. Experiments were performed upon multilayer mirrors, measuring reflectivity loss after exposure to debris. Gas jets were implemented to literally blow away the debris from the condenser optical surface. These were marginally effective, but have been recently revisited with higher pressure valves. Magnetic fields were found to be rather ineffective, indicating that debris were largely neutrally charged. Finally, a background gas had been found to be effective in reducing the very low mass debris, and a $200 \mathrm{mT}$ He background gas was always used in our target chambers. (More recently a similar background of $\mathrm{Kr}$ gas and a thin wire target reduced debris another factor of 10.)

In view of these difficulties in reducing debris it was decided to seek targets that simply produced little debris to be mitigated. These included low mass thin-film targets and cryogenic targets.

Mass-limited target conversion efficiency was studied using gold coated on a $1.3 \mu \mathrm{m}$ plastic backing. This concluded our work from $0.7 \times 10^{11} \mathrm{~W} / \mathrm{cm}^{2}$ up to an intensity of $2.8 \times 10^{11} \mathrm{~W} / \mathrm{cm}^{2}$. The results showed burnthrough occurring at a gold depth greater than $300 \mathrm{~nm}$ for $.28 \mathrm{TW} / \mathrm{cm}^{2}$ and at $220 \mathrm{~nm}$ for $.12 \mathrm{TW} / \mathrm{cm}^{2}$, as opposed to 50 $\mathrm{nm}$ for $.07 \mathrm{TW} / \mathrm{cm}^{2}{ }^{1}$ The data from this work can be seen in Figure 10 . This established the coating thickness that would be required to produce the same XUV emission as seen from a solid target. These results extended the work of past inertial fusion research on mass ablation rates, which had only gone down to intensities of 1 
$x 10^{12} \mathrm{~W} / \mathrm{cm}^{2}$. It showed a logarithmic change in material ablation rate as a function of laser intensity on target.

Debris however was not significantly reduced with such a target due to excessive lateral heat spreading in the thin film. Burn holes in the plastic film were often 1-2 $\mathrm{mm}$, even though the laser focal spot size was only $125 \mu \mathrm{m}$. Yet the diameter of the metal removed from the film could easily be $8-10 \mathrm{~mm}$ ! This was evidenced in a large amount of hydrocarbon deposit moving behind the coated film plus late-time metal eroding from the front surface of the film.

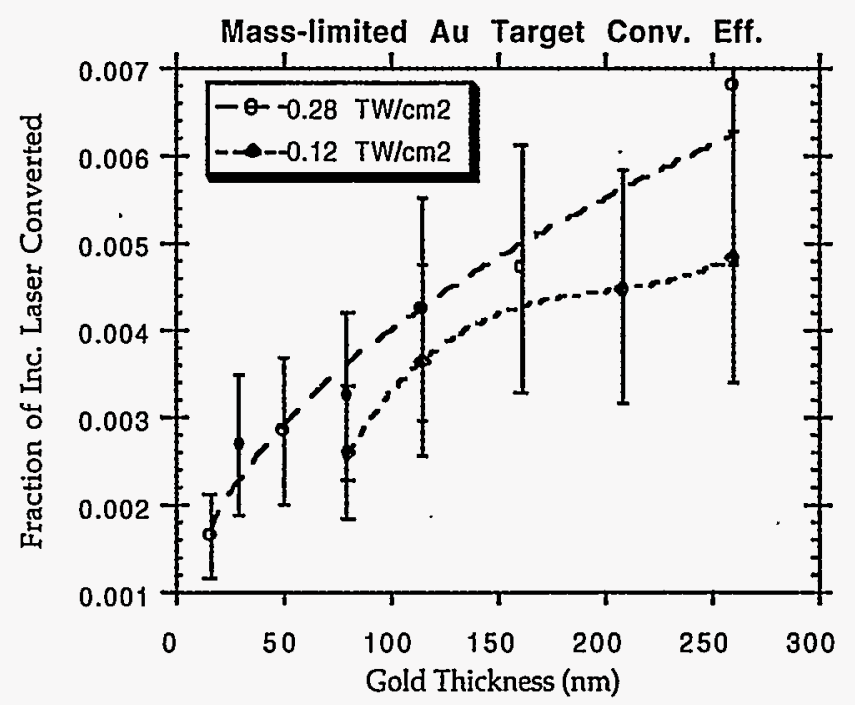

Figure 10. EUV yield as a function of metal thickness demonstrating burn-thru depth

Another more viable target candidate was the cryogenic Xe target. Experiments were performed to measure the EUV yield from frozen Xe and demonstrated that at $13.5 \mathrm{~nm}$ Xe produced the same yield as copper targets (see discussion in the next section of this paper). This was about two-thirds that produced by gold, but we could easily accept a factor of two reduction in yield, if debris concerns could be dramatically ameliorated. Presumably, even if the Xe generated debris that struck a multilayer mirror, the debris would rapidly evaporate, leaving no trace deposits. In fact this was found to be true. Yet damage did occur to the multilayer coating, indicating that solid debris was still reaching the condenser surface. To reduce the amount of Xe debris we began a program to develop a pellet injector for cryogenic Xe. Built by Oak Ridge National Laboratory, our first injector produced cylinders of Xe that were $1.2 \mathrm{~mm}$ long by $0.5 \mathrm{~mm}$ in diameter. An optical monitor recorded the fall of each pellet and predicted its entry time into the laser target region. The device is shown in Figure 11. 


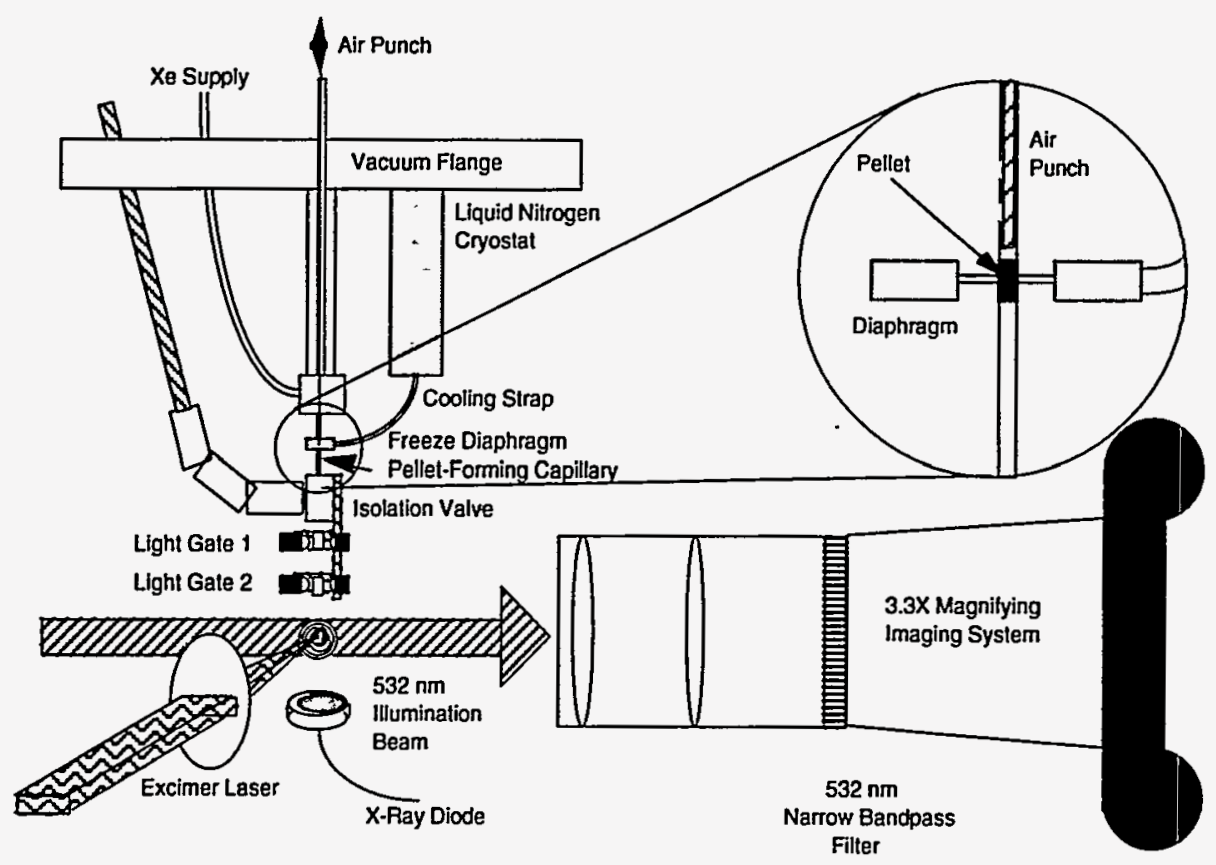

Figure 11. Schematic diagram of Xe pellet injector experiment

Fragments were seen to leave the target with velocities of $\sim 1 \mathrm{~km} / \mathrm{sec}$ at times of up to $2 \mathrm{msec}$ after laser irradiation. But all exposed surfaces showed no build-up of debris.

In a related attempt the Univ. of Central Florida group under W. Silfvast developed an ice target, showing that strong lithium-like oxygen lines were produced with 1.06 $\mathrm{mm}$ illumination in the $13.5 \mathrm{~nm}$ region.

\section{VUV Spectroscopy of Laser-Plasma Sources}

The $13.5 \mathrm{~nm}$ region of the spectrum provided serious challenges to the theorist in calculating ionization stages, opacity, and radiation transport. Thus we opted to depend upon direct measurement of the VUV spectra of a variety of candidate materials to infer relative efficiencies and to determine if optimization was possible by moving to nearby wavelengths. A transmission grating spectrograph was used to record laser-target spectra with $0.1 \mathrm{~nm}$ resolution on Kodak 101 film over 2-20 nm.

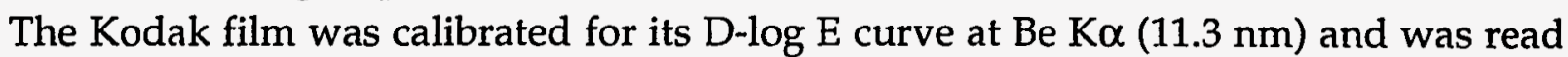
with a high spatial resolution PDS scanning microdensitometer. The grating was a 5000 line $/ \mathrm{mm}$ gold grating, $209.5 \mathrm{~nm}$ thick with a $100 \mu \mathrm{m} \times 10 \mathrm{~mm}$ dispersion slit, that was purchased from XOpt Inc. It was operated $58 \mathrm{~cm}$ from the target and the film plane was a further $25 \mathrm{~cm}$ from the grating. Prior experience in use of this grating had shown that the wavelength identification on film was virtually identical to the theoretically identified positions. ${ }^{13}$ 
Grating experiments were performed using the Sandia/California $\mathrm{KrF}$ Laser Plasma Source providing $1 \mathrm{~J}$ in $32 \mathrm{~ns}$ at $248 \mathrm{~nm}$ at a repetition rate of up to $100 \mathrm{~Hz}$.

Intensities were varied from $1-2 \times 10^{11} \mathrm{~W} / \mathrm{cm}^{2}$. Additional experiments on EUV transport were conducted with the Jamar Technology Inc., XeCl laser at $308 \mathrm{~nm}$. The laser at Jamar was adjusted to produce a $4.5 \mathrm{~ns}, 12 \mathrm{~ns}, 25 \mathrm{~ns}$, and $40 \mathrm{~ns}$ pulse with approximately $0.4 \mathrm{~J} /$ pulse, providing intensities of $0.3-15 \times 10^{11} \mathrm{~W} / \mathrm{cm}^{2}$ on target. Laser focal spot size was maintained at $125 \mu \mathrm{m}$ diameter with the LPS and $90 \times 135$ $\mu \mathrm{m}$ with the $\mathrm{XeCl}$ laser.

Our targets contained either gold in a .012" plating on stainless steel or thick sheet targets of the tin and copper. Cryogenic xenon was formed with a liquid helium cold finger. Diagnostics included a multilayer $x$-ray diode (XRD) centered at $14.2 \mathrm{~nm}$ with an $11 \%$ bandwidth, and detectors for laser energy and pulseshape monitoring. The XRD assured a continuously reproducible EUV yield and it provided a measure of constant laser intensity. Multiple shots were required to obtain usable exposures on film. The number of superimposed shots ranged from 14 to 60 . Figure 12 shows the configuration used in these experiments.

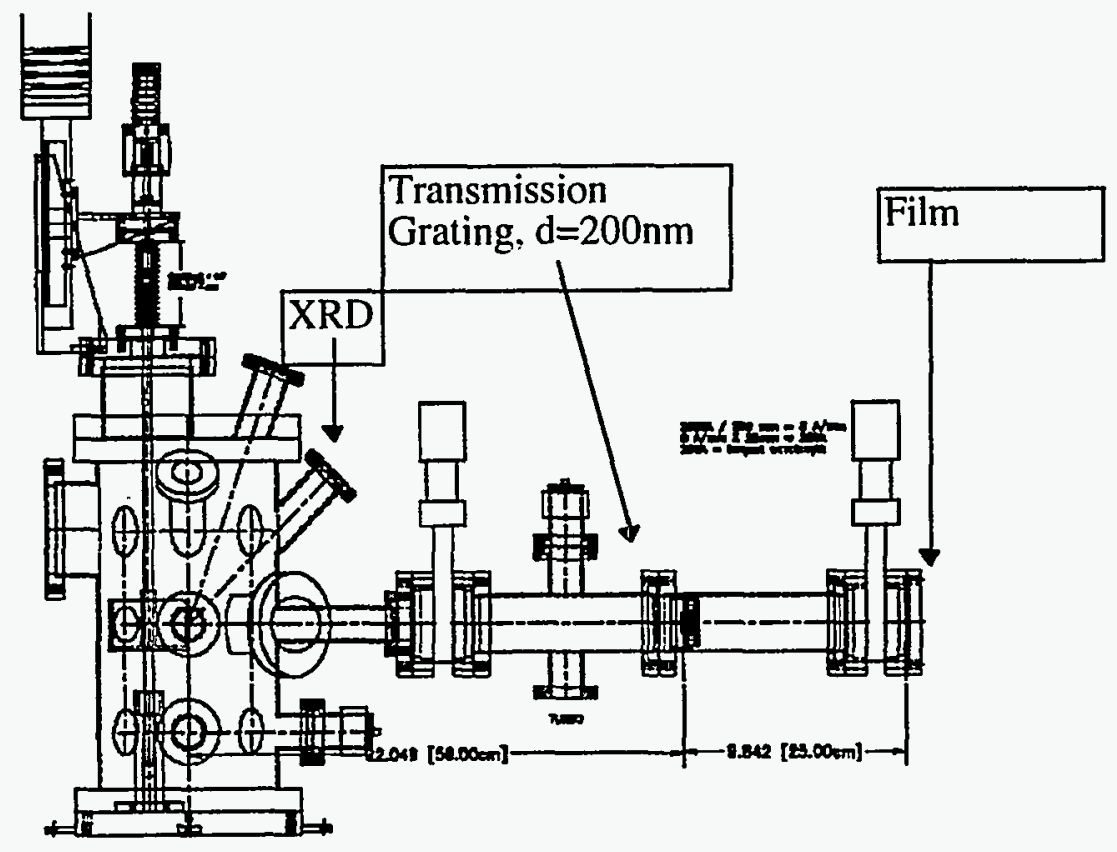

Figure 12. Configuration for use of transmission grating spectroscopy

The VUV spectra obtained from laser-irradiated targets using $248 \mathrm{~nm}$ was largely continuous with little significant small-scale structure. This was expected, since analytical theory and code calculations indicated that radiation was generated at fairly high ion densities on the order of $10^{21} \mathrm{~cm}^{-3}$. At these densities characteristic lines were broadened by pressure broadening and by self-absorption along the path, so that the observed spectrum was smeared into a continuum. This was to be 
contrasted with the spectra observed with $1.06 \mu \mathrm{m}$ and $0.532 \mu \mathrm{m}$ laser illumination, where materials such as tin produced clear, peaked lines in the EUV. ${ }^{6}$

The raw data was convolved with the grating efficiency in multiple overlaid orders. Calibrations of the grating indicated that there was a significant $(\sim 20 \%)$ second order contribution and very small higher order contributions. This was contrary to the theory that equal lines and spaces in a grating produce only odd orders and said much about the thickness, the squareness of the grating bar cross-sections, and the uniformity of the bars and spaces.

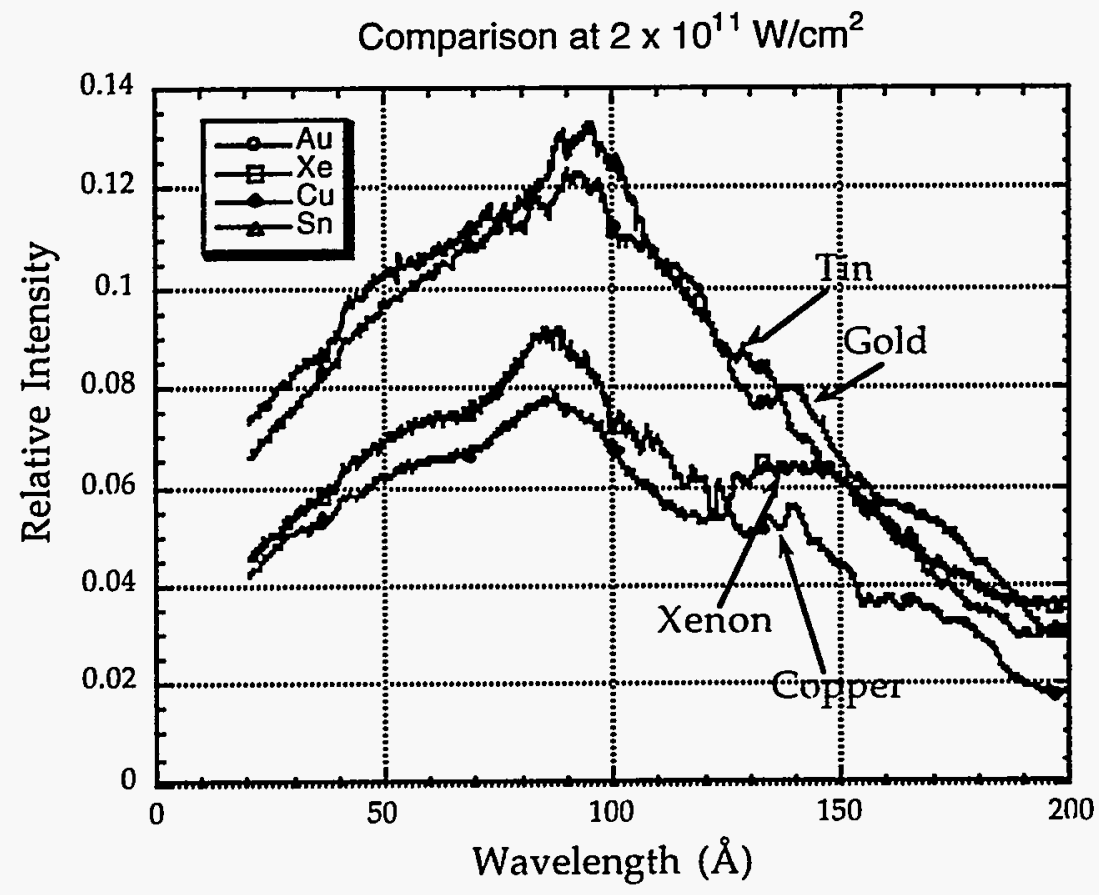

Figure 13. Comparison of Material Spectra at $2 \times 10^{11} \mathrm{~W} / \mathrm{cm}^{2}$

After removing the second order contribution from the spectra, the images appeared as shown in Figure 13 for $\mathrm{Au}, \mathrm{Xe}, \mathrm{Cu}$, and $\mathrm{Sn}$ at $2 \times 10^{11} \mathrm{~W} / \mathrm{cm}^{2}$. Note the small peaks appearing at 12.9 and $13.3 \mathrm{~nm}$ in tin, which may represent $6 \mathrm{f}-4 \mathrm{~d}$ transitions in Sn VII. Also note the relative lack of structure in the spectrum, showing that small variations in chosen wavelength for excimer-driven lithography will make only slight improvements in conversion efficiency. At only half this intensity on target $\left(1 \times 10^{11} \mathrm{~W} / \mathrm{cm}^{2}\right)$ the spectra changed noticeably and are displayed in Figure 14 below.

The only leader at $13.5 \mathrm{~nm}$ was the gold target with approximately $50 \%$ higher output than all others. Note also that a factor of two increase in laser intensity resulted in a factor of three increase in EUV yield in the $13.5 \mathrm{~nm}$ region. The work at Jamar was designed to determine the effect of plasma shuttering upon EUV conversion efficiency. This work demonstrated unequivocally that UV pulses exceeding $25 \mathrm{~ns}$ form a large plasma through which the EUV radiation must 
propagate, which essentially shutters this radiation and reduces net conversion into the EUV.

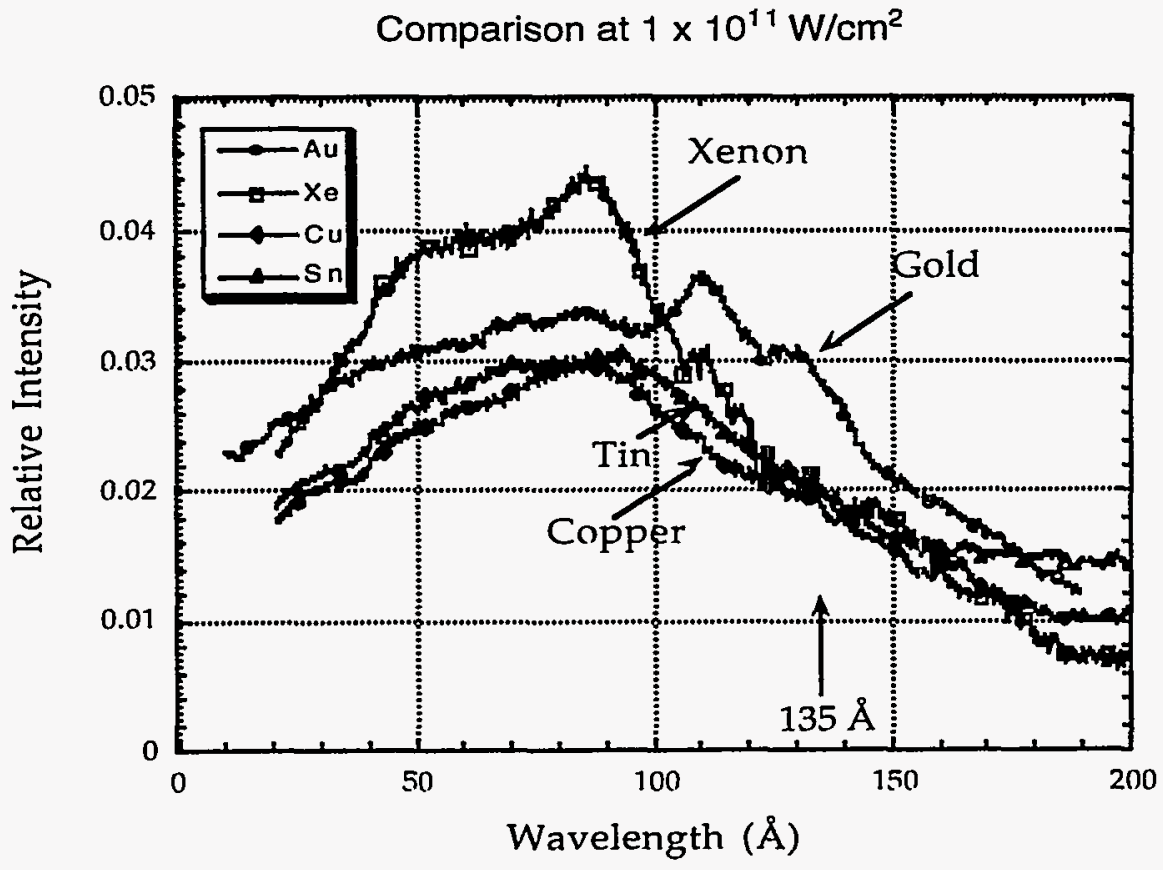

Figure 14. Comparison of material spectra at $1 \times 10^{11} \mathrm{~W} / \mathrm{cm}^{2}$

\section{VUV Shuttering Explained}

The data recorded at Jamar was motivated by prior studies of our group that showed a shuttering of the emitted EUV radiation with laser pulselengths of $32 \mathrm{~ns}$ and 47 ns. ${ }^{1}$ The Jamar $\mathrm{XeCl}$ laser was modified to operate at a variety of pulselengths, and conversion efficiency measurements were made as a function of intensity for each pulselength. For pulses of $4.5 \mathrm{~ns}, 12 \mathrm{~ns}$, and $25 \mathrm{~ns}$ conversion efficiency remained at approximately the same high level. At $40 \mathrm{~ns}$ conversion into the EUV fell to onequarter of this value as seen in Figure 15.

In another experiment two pulses of 5 ns duration were produced, separated by an arbitrary amount. The first yielded a plasma plume through which the second was focussed. With sufficient spacing in time ( $32 \mathrm{~ns})$, the EUV emission from the second pulse was clearly shuttered, just as the equivalent long pulse had been. This conclusively established the cause of the reduction of excimer laser-plasma source EUV radiation with long pulses. 


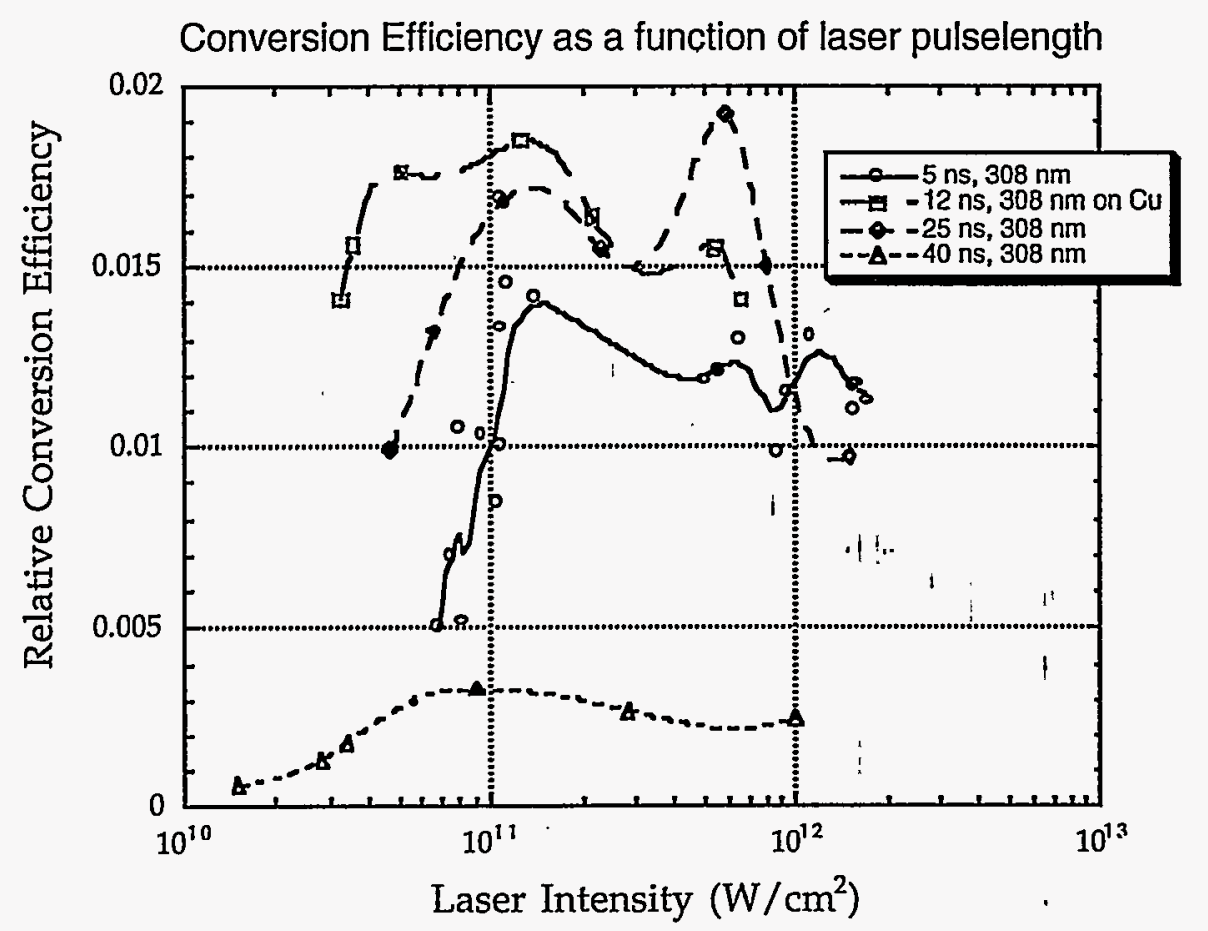

Figure 15. Measured conversion efficiencies with UV: lasers

\section{Conclusions}

EUV radiation produced by short wavelength lasers at $248 \mathrm{~nm}$ or $308 \mathrm{~nm}$ has the advantage of producing slowly varying spectra that will be insensitive to the choice of the spectral reflectivity peaks for EUVL optics. On the other hand, the lack of isolated lines limits the maximum source spectral brightness available:

Pulselengths of $25 \mathrm{~ns}$ and shorter seem to totally avoid the problem of plasma plume shuttering, eliminating one area of concern in the use of excimer lasers, whose pulselengths tend to be longer than solid state lasers.

The debris issue, however, motivates one to move to longer wavelengths. Absorption occurs at a greater distance from the target solid surface and at lower densities than would be experienced with a short wavelength source. Since the critical density for absorption varies as the electron density squared, a change in wavelength from $.248 \mu \mathrm{m}$ to $1.06 \mu \mathrm{m}$ results in absorption in the plasma at densities one sixteenth lower! This produces a far lower shock reaching solid densities, and far less debris is observed. Additionally one gains a smaller source at $1.06 \mu \mathrm{m}$, because most such lasers generate pulses with 8-10 ns pulselengths. The shorter pulse causes a smaller source with a more Lambertian emitted angular distribution. 
Other target types may now need to be developed in order to reduce debris to an acceptable level.

As a result of this work, we are able to make confident predictions of the required laser pulselength, laser average power, laser wavelength, and the concomitant source $x$-ray size, source $x$-ray angular distribution, and debris production. We understand how the conversion to $x$-rays scales with laser intensity and wavelength, and what the optimum operating regions are. Minimizing the mass of the lasertarget is the correct way to minimize debris, but it will take further work with geometrically-small targets, cryogenic targets, and gas puff targets to perfect such a system.

A laser-plasma $x$-ray stepper will be the source of our next generation 4 Gbit memories in the next century. This LDRD has taken the first baby steps in that direction.

\section{References}

1. P. Rockett, J. Hunter, R. Kensek, R. Olson, G. Kubiak, and K. Berger, "XUV Conversion Efficiency in a Low-Intensity KrF Laser Plasma for Projection Lithography," OSA Proc. on Soft X-ray Projection Lithography, Vol. 12, Monterey, CA, April 10-12 1991.

2. R. Kodama, K. Okada, N. Ikeda, M. Mineo, K. A. Tanaka, T. Mochizuki, and C. Yamanaka, J. Appl. Phys. vol. 59, 3050 (1986).

3. R. Popil, P. D. Gupta, R. Fedosejevs, and A. A. Offenberger, "Measurement of KrFlaser-plasma $\mathrm{x}$-ray radiation from targets with various atomic numbers," Phys. Rev. $A$ vol. 35, 3874 (1987).

4. M. Chaker, H. Pépin, V. Bareau, B. Lafontaine, I. Toubhans, R. Fabbro, and B. Faral, "Laser plasma x-ray sources for microlithography," J. Appl. Phys. vol. 63, 892 (1988).

5. R. L. Kauffman and D. W. Phillion, "X-ray Production Efficiency at $130 \AA$ from Laser-Produced Plasmas," OSA Proceeding on Soft-X-Ray Projection Lithography, J. Bokor, ed., Vol. 12, 68 (1991).

6. R. C. Spitzer, R. L. Kauffman, T. Orzechowski, D. W. Phillion, and C. Cerjan, "Soft $\mathrm{x}$-ray production from laser produced plasmas for lithography," J. Vac. Sci. Technol. $B$ vol. 11(6), 2986 (Nov/Dec 1993).

7. J. M. Bridges, C. L. Cromer, and T. J. McIlrath, "Investigation of a laser-produced plasma VUV light source," Appl. Opt. vol. 25, 2208 (1986). 
8. R. H. Day, P. Lee, E. B. Salomon, and D. J. Nagel, "Photoelectric Quantum Efficiencies and Filter Window Absorption Coefficients from $20 \mathrm{eV}$ to $10 \mathrm{keV}, " \mathrm{~J}$. Appl. Phys. vol. 52, 6965 (1981).

9. W. M. Burton and B. A. Powell, "Fluorescence of Tetraphenyl-Butadiene in the Vacuum Ultraviolet," Appl. Opt. vol. 12, 87 (1973).

10. L. R. Canfield, J. Kerner, and R. Korde, "Stability and quantum efficiency performance of silicon photodiode detectors in the far ultraviolet," Appl. Opt. vol. 28,3940 (1989).

11. J. W. McConkey, T. Crouch, and J. Tomc, "Sensitivity response of channel electron multipliers and channel plates to the polarization of VUV radiation," Appl. Opt. vol. 21, 1643 (1982).

12. D. L. Matthews, E. M. Campbell, N. M. Ceglio, G. Hermes, R. Kauffman, L. Koppel, R. Lee, K. Manes, V. Rupert, V. W. Slivinsky, R. Turner, and F. Ze, "Characterization of laser-produced plasma $\mathrm{x}$-ray sources for use in $\mathrm{X}$-ray radiography," J. Appl. Phys. vol. 54, 4260 (1983).

13 P. D. Rockett, J. Hunter, J. Bradley III, J. Gahl, R. Peterson, A. Zhitlukhin, N. Arkhipov, V. Bakhtin, D. Toporkov, I. Ovchinnokov, "VUV Spectroscopy of Armor Erosion from Plasma Gun Disruption Simulation Experiments," to be published in Fusion Engineering. 


\section{Distribution}

$\begin{array}{cclc}\text { Copies } & \text { Mailstop } & \text { Name } & \text { Department } \\ 1 & 0859 & \text { S. Guiterrez } & 2527 \\ 1 & 9409 & \text { K. W. Berger } & 8250 \\ 1 & 1415 & \text { J. A. Hunter } & 1112 \\ 1 & 9161 & \text { K. D. Krenz } & 8250 \\ 1 & 9409 & \text { G. Kubiak } & 8250 \\ 1 & 1187 & \text { R. E. Olsen } & 9571 \\ 8 & 0859 & \text { P. D. Rockett } & 2527 \\ 2 & 9409 & \text { R. Stulen } & 8250 \\ & & & \\ 1 & 9018 & \text { Central Technical Files } & 8940-2 \\ 5 & 0899 & \text { Technical Library } & 4414 \\ 2 & 0619 & \text { Review \& Approval Desk } & 12690 \\ & & \text { for DOE/OSTI } & \\ 1 & 0188 & \text { Chuck Meyers, LDRD office } & 4523\end{array}$

